\title{
Perceived value of applying Information Communication Technology to implement guidelines in developing countries; an online questionnaire study among public health workers
}

\author{
Pasipanodya Ian Machingura1, Olawumi Adekola², Eunice Mueni ${ }^{3}$, Omo Oaiya ${ }^{4}$, Lars L \\ Gustafsson ${ }^{5}$, Richard F Heller ${ }^{6}$ \\ 1. College of Health Sciences, University of Zimbabwe, Zimbabwe \\ 2. International Health Management Services, Nigeria \\ 3. African Institute for Development Policy, Kenya \\ 4. West and Central African Research and Education Network, Nigeria \\ 5. Division of Clinical Pharmacology, Department of Laboratory Medicine, Karolinska Institute, Sweden \\ 6. People's Open Access Education Initiative (Peoples-uni), UK
}

\begin{abstract}
Introduction: Practice guidelines can be used to support healthcare decision making. We sought to identify the use, and barriers to the implementation, of electronic based guidelines to support decisionmaking in maternal and child healthcare $(\mathrm{MCH})$ and the rational use of medicines, in developing countries.

Methods: Graduates who had gained the Master of Public Health degree through the Peoples-uni (postgraduate public health education in developing countries) were sent an online survey questionnaire which had been piloted. Two reminders were sent to non-respondents at intervals of 10 days. Results were explored using descriptive analyses.

Results: 44 of the potential 48 graduates from 16 countries responded - most were from Africa. $82 \%$ and $89 \%$ of respondents were aware of guidelines on $\mathrm{MCH}$ and the rational use of medicines respectively. Electronic guidelines were more available in university hospitals than in provincial hospitals or rural care. All respondents thought that guidelines could improve the delivery of quality care, and 42 (95\%) and 41 (93\%) respectively thought that computers and mobile or smartphones could increase the use of guidelines in service delivery. Lack of access to computers, need to buy phone credit, need for training in the use of either computerized or phone based guidelines and fear of increased workload were potential barriers to use.

Conclusion: There is support for the use of electronic guidelines despite limited availability and barriers to use in developing countries. These findings, and other literature, provide a guide as to how the further development of ICT based guidelines may be implemented to improve health care decision making.
\end{abstract}

Keywords: Clinical Practice Guidelines, Information Communication Technology (ICT),Maternal and Child Health (MCH), Rational Use of Medicines. .

Abbreviations: Maternal and Child Health (MCH), Information Communication Technology (ICT)

Correspondence: rfheller@peoples-uni.org

DOI: 10.5210/ojphi.v6i2.5368

Copyright $@ 2014$ the author(s) 
This is an Open Access article. Authors own copyright of their articles appearing in the Online Journal of Public Health Informatics. Readers may copy articles without permission of the copyright owner(s), as long as the author and OJPHI are acknowledged in the copy and the copy is used for educational, not-for-profit purposes.

\section{Introduction}

Clinical practice guidelines have the potential to enhance the quality of healthcare by promoting consistent clinical decision making based on best evidence. Guidelines can be made available either electronically or in print. Guidelines in a printed form may not be updated promptly enough to keep pace with rapidly emerging evidence. In addition, the publication, dissemination and receipt of feedback from stakeholders create other physical limitations to the value of printed guidelines [1] [2]. An important requirement for the development of both electronic and printed guidelines is that they should involve the key stakeholder groups that are going to implement the guidelines [3] [4] [5]. Well developed and interactive guidelines using information and communication technology (ICT) may be able to at least partly meet these challenges [6] [7].

The world has had a proliferation of ICT systems revolutionising how human knowledge is recorded, stored and retrieved. Pre-ICT era information retrieval would entail significant time in a library and physical access to hard copy material. However, use of ICT currently enables an individual to carry out a search and obtain the information on a computer or mobile device. Healthcare professionals in developed countries have benefited immensely from the informatics revolution. On the other hand, low and middle income countries are the least advanced in ICT infrastructure and service provision, whilst they have the burden of the majority of world's health issues as well as a shortage of healthcare workers [6] [8]. However, the potential of mobile phones and the Internet revolution are apparent across all continents including rural parts of Africa and Asia. Translation of clinical practice guidelines into an electronic form (whether on computers or smartphones) may utilise this revolution and enhance their accessibility [9] [10].

It was observed in Botswana that hard copy versions of guidelines were kept locked in rooms in healthcare facilities and rarely referenced by clinicians, while smartphones loaded with medical applications and resources were a useful information retrieval tool for clinicians working in remote areas [6]. In a study among medical professionals in a national hospital in Kenya, some of the participants indicated awareness of only a few specific guidelines from the ministry of Health [11]. Similar poor access to printed guidelines was recently documented in three African countries (Burkina Faso, Ghana and Tanzania) [2].

This study sought to find out, amongst a group of developing country healthcare professionals mainly from Africa, if guidelines for Maternal and Child Healthcare (MCH) as well as guidelines for the rational use of medicines were available either in print or electronically. The study also sought to discover whether the respondents were aware of the availability of guidelines, whether they used the guidelines in practice and what they considered to be the potential future value and limitations to the use of computers and smartphones to access guidelines to support decision making.

\section{Methods}

The People's Open Access Education Initiative (Peoples-uni http://peoples-uni.org) [12] provides online education in Public Health to health professionals in developing countries. The first set of Alumni who had graduated with the Master of Public Health degree, awarded by a partner 
Manchester Metropolitan University in 2012 and 2013 provided the sampling frame for this survey. Approval for the study was granted by the Peoples-uni Leadership Group.

A questionnaire, based on an initial literature review [2] [4] [13] [14], was developed and piloted informally among the author members of the Alumni group. The questions included demographic information about the respondents, as well as information about considered value of ICT based guidelines in general as well as in relation to $\mathrm{MCH}$ and rational use of medicines. An online survey form was prepared, using Eko-konnect (a cluster of the Nigerian Research and Education Network, (ngREN) http://eko-konnect.org.ng/). All potential respondents were sent a message via the discussion forum to which they are subscribed as Alumni or students, and two reminders sent to non-responders at intervals of 10 days. Data collection was completed within one month in the second half of 2013. Results were explored using descriptive analyses.

\section{Results}

Responses were obtained from 44 of the 48 potential respondents, working in 16 countries. Most of the respondents came from Africa, see Table 1.

Table 1. Region in which the respondents worked $(n=44)$

\begin{tabular}{|l|l|}
\hline Region of respondent & Number \\
\hline West Africa & 21 \\
\hline East Africa & 11 \\
\hline Southern Africa & 7 \\
\hline Asia & 5 \\
\hline Total & 44 \\
\hline
\end{tabular}

19 of the respondents were physicians, 3 were nurses, and 11 were non-clinical Public Health personnel. The other 11 respondents came from various health related areas including pharmacy, laboratory science or worked as clinical community or Public Health personnel. 13 worked directly in maternal health, 25 in child health, and the remainder in a number of clinical or nonclinical areas, although there was overlap between the groups with some respondents reporting more than one area of work. The respondents reported multiple roles which included 20 as managers, 16 clinicians, 11 teachers and 24 researchers. The majority completed the survey themselves, although 3 asked others to assist.

Guidelines were given as the most frequent sources of information to guide $\mathrm{MCH}$, with each of the other options given (Continuing Professional Education, reliance on training and asking colleagues) also being quoted - in that order. $36(82 \%)$ of the respondents said they were aware of guidelines on MCH service delivery, and 39 (89\%) were aware of guidelines for the rational use of medicines or the essential drugs list.

Table 2 shows that guidelines were available in paper or electronic form, with fewer available in electronic form for rational use of medicines than for $\mathrm{MCH}$, and fewer in rural than provincial or university hospital care. 
Table 2. Format in which guidelines were reported to be available. Percentage calculations based on 44 total respondents)

\begin{tabular}{|l|l|l|l|l|l|l|l|l|l|l|}
\hline \multirow{2}{*}{$\begin{array}{l}\text { Type of } \\
\text { care } \\
\text { facility }\end{array}$} & \multicolumn{3}{|l|}{ Maternal and Child Healthcare } & \multicolumn{3}{l|}{ Rational use of medicines } \\
\cline { 2 - 9 } & Paper & Electronic & Both & $\begin{array}{l}\text { Any } \\
\text { electronic } \\
\text { form }\end{array}$ & $\begin{array}{l}\text { Don't } \\
\text { know }\end{array}$ & Paper & Electronic & Both & $\begin{array}{l}\text { Any } \\
\text { electronic }\end{array}$ & $\begin{array}{l}\text { Don't } \\
\text { know }\end{array}$ \\
\hline $\begin{array}{l}\text { University } \\
\text { hospital } \\
\text { care } \\
\text { (private or } \\
\text { public) }\end{array}$ & 8 & 5 & 21 & $26(59 \%)$ & 2 & 16 & 3 & 17 & $20(45 \%)$ & 3 \\
\hline $\begin{array}{l}\text { Provincial } \\
\text { hospital } \\
\text { care }\end{array}$ & 17 & 2 & 13 & $15(34 \%)$ & 4 & 19 & 3 & 9 & $12(27 \%)$ & 8 \\
\hline Rural care & 18 & 3 & 10 & $13(30 \%)$ & 6 & 21 & 1 & 5 & $6(14 \%)$ & 12 \\
\hline
\end{tabular}

Note: numbers add to more than 44 in rows for both $\mathrm{MCH}$ and rational use of medicines, where guidelines were available in more than one format.

$34(77 \%)$ and $35(80 \%)$ of the respondents had access to the guidelines for MCH and rational use of medicines, respectively.

All of the respondents thought that guidelines could improve the delivery of quality care, and 42 $(95 \%)$ and $41(93 \%)$ respectively thought that computers and mobile or smartphones could increase the use of guidelines in service delivery.

Hard (printed) copies of guidelines were thought likely to be the most effective guideline format by $11(25 \%)$ of the respondents, while $25(57 \%)$ thought that electronic or computerised formats, and $10(23 \%)$ thought that mobile or smartphones were the preferred option. A number of respondents mentioned that this would depend on local circumstances.

Twenty six (59\%) of the respondents were aware of the guidelines for the Integrated Management of Childhood Illness. Others mentioned that they were aware of guidelines relating to malaria, HIV/AIDS, neonatal resuscitation, health management information (weekly surveillance) and WHO and UNAIDS guidelines.

Table 3 shows the challenges to the implementation of guidelines - lack of access to computers would be a major limitation to the implementation of a guidelines system, and training would be required. Lack of funds to purchase phone credit could be a limitation to the use of phone based guidelines. Fear of increased workload was thought to be a limitation by only around one third of respondents. Other reasons given included lack of access to maintenance, connectivity, electricity or phone networks. 
Table 3. Challenges forseen in the implementation of guidelines using computers and mobile or smartphones. Numbers (percentage of total 44 respondents).

\begin{tabular}{|l|l|l|}
\hline Potential challenges & Computer & Mobile/smart phone \\
\hline Lack of access & $33(75 \%)$ & $16(36 \%)$ \\
\hline Lack of ability to use & $21(48 \%)$ & N/a \\
\hline $\begin{array}{l}\text { Lack of funds to purchase } \\
\text { credit on the phone }\end{array}$ & N/a & $28(64 \%)$ \\
\hline $\begin{array}{l}\text { Requires training of health } \\
\text { care providers }\end{array}$ & $33(75 \%)$ & $25(57 \%)$ \\
\hline Fear of increased workload & $15(34 \%)$ & $12(27 \%)$ \\
\hline
\end{tabular}

N/a - not asked

\section{Discussion}

There was good response rate among the Alumni of the online MPH programme, who were working in a number of countries - mostly in Africa - and in fields relevant to the scope of the survey.

Respondents were aware of the existence of guidelines for both $\mathrm{MCH}$ and rational use of medicines. Availability seemed to vary according to the site of the care facility, with rural care being more likely to have paper based guidelines and less likely to have electronic guidelines than urban university hospitals.

All respondents thought that guidelines could improve the quality of care and most that this applied to those available through either computers or mobile phones. The most effective mode of delivery was thought to be the computer, with fewer picking hard copies or phone, although this could vary according to local circumstances. Lack of access to computers, however, would be a limitation, as would the need to buy phone credit. Practitioners would require training in the use of either computerised or phone based guidelines, but only one third and one quarter of the respondents respectively thought that a fear of increased workload would be a barrier to their use.

These results are consistent with a study among healthcare workers in Burkinao Faso which found that there was a willingness to use modern technology and guidelines in the workplace, but a concern about the working time required and the training necessary [9]. The need for training is a consistent finding, and any attempt to increase the use of ICT based guidelines should be accompanied by appropriate training. The costs of implementing such a system should therefore include the costs of training. In addition, consideration of how to increase access to ICT based guidelines to improve decision support in healthcare should include the ease of use of the system and its perceived usefulness by the healthcare workers [4] [5] [6] [15].

There have been calls over the years for better access to information using the Internet [15] and specifically how guideline use might enter the digital age [1]. From the developing world, a Kenyan study found an expressed desire for the increased availability of ICT to help with access to health information [11], although a study among rural Nigerian $\mathrm{MCH}$ workers found that there 
were a number of endemic barriers and end-user preferences that would limit the adoption of ICT in health care [16].

There is potential for ICT to make a contribution to health care, and hence the health of the population, if it is made more readily and openly available. Involvement in the planning and implementation [4] [5] and belief in the benefits [5] have previously been shown to improve intentions to use ICT based decision support systems. It is difficult to demonstrate the potential benefit of guideline implementation to improve health outcomes [13]. Mobile phone reminders have, however, been shown to improve antenatal care attendance [17]. Education, audit and outreach have been shown to improve MCH outcomes substantially [18] [19], but these were in the context of a package of interventions. ICT based guidelines, if they are to be beneficial, are likely to need to be part of a broad package of interventions aimed at improving care and the use of evidence based interventions.

Study limitations include the relatively small sample size and the lack of validation of the answers to the survey questions. Hard copies of the survey form were not used in this fully online survey.

The use as the sampling frame of the graduates of a high quality online MPH programme, working themselves in various parts of the health care system in developing countries, has a number of advantages. They have expertise in the critical evaluation of information and the implications of ICT for education, are used to collaborating and sharing information online, and understand the realities of healthcare in developing countries. Our study also fills the lack of knowledge on the extent to which various guidelines are available in resource strained countries and the attitudes to make them available in digital format.

\section{Conclusion}

Our study adds to the literature in that it comes from a wide spectrum of developing world settings amongst a group of health professionals well trained through an MPH programme. We report strong support for the use of guidelines, as well as for the use of ICT delivery to help their implementation. Currently electronic guidelines have limited availability other than in university hospitals, and the barriers to use identified offer a template for action. These findings, together with other literature and various initiatives for action, provide a guide as to how the further development of ICT based guidelines may be implemented to improve health care decision making.

\section{Financial Disclosure}

No funding was sought or obtained for this study, other than support to LLG as acknowledged below.

\section{Competing Interests}

No competing interests 


\section{Acknowledgements}

This study was in part supported by funds from Swedish Research Council (funds to Lars L Gustafsson, VR 2011-3440), European Union Project ei4Africa (e-infrastructures for Africa, grantagreement 313582) and Karolinska Institutet.

\section{References}

1. Olver IN, von Dincklage J. 2013. It is time for clinical guidelines to enter the digital age. Med J Aust. 199, 569-70. PubMed http://dx.doi.org/10.5694/mja13.10862

2. Baker U, Tomson G, Somé M, Kouyaté B, Williams J, et al. 2012. "How to know what you need to do": a cross-country comparison of maternal health guidelines in Burkina Faso, Ghana and Tanzania. Implement Sci. 7(31). PubMed

3. National Collaborating Centre for Methods and Tools 2011. Critically appraising practice guidelines: The AGREE II instrument. Hamilton, ON: McMaster University. (Updated 01 November, 2013). Retrieved from http://www.nccmt.ca/registry/view/eng/100.html

4. Blank A, Prytherch H, Kaltschmidt J, Krings A, Sukums F, et al. 2013. "Quality of prenatal and maternal care: bridging the know-do gap" (QUALMAT study): an electronic clinical decision support system for rural Sub-Saharan Africa. BMC Med Inform Decis Mak. 13(44). PubMed:

5. Sambasivan M, Esmaeilzadeh P, Kumar N, Nezakati H. 2012. Intention to adopt clinical decision support systems in a developing country: effect of physician's perceived professional autonomy, involvement and belief: a cross-sectional study. BMC Med Inform Decis Mak. 12(142). PubMed

6. Littman-Quinn R, Luberti A, Kovarik C. 2013. mHealth to Revolutionize Information Retrieval in Low and Middle Income Countries: Introduction and Proposed Solutions Using Botswana as Reference Point. In: Studies in Health Technology and Informatics. 192, 894898 Lehmann C, Ammenwerth E, Nøhr C, editors. MEDINFO 2013. IOS Press

7. Gustafsson LL, Wettermark B, Godman B, Andersén-Karlsson E, Bergman U, et al. 2011. The "wise list"- a comprehensive concept to select, communicate and achieve adherence to recommendations of essential drugs in ambulatory care in Stockholm. Basic Clin Pharmacol Toxicol. 108, 224-33. PubMed http://dx.doi.org/10.1111/j.1742-7843.2011.00682.x

8. Lucas H. 2008. Information and communications technology for future health systems in developing countries. Soc Sci Med. 66, 2122-32. http://dx.doi.org/10.1016/j.socscimed.2008.01.033

9. Zakane SA, Gustafsson LL, Tomson G, Loukanova S, Sié A, et al. 2014. Guidelines for maternal and neonatal "point of care": needs of and attitudes towards a computerized clinical decision support system in rural Burkina Faso. Int J Med Inform. 83, 459-69. PubMed http://dx.doi.org/10.1016/j.ijmedinf.2014.01.013

10. Afarikumah E. 2014. Electronic health in Ghana: current status and future prospects. Online J Public Health Inform. 5(3), 230. PubMed http://dx.doi.org/10.5210/ojphi.v5i3.4943 
11. Gatero DG. 2011. Utilization of ICTs for Accessing Health Information by Medical Professionals in Kenya: A Case Study of Kenyatta National Hospital [Internet]. Journal of Health Informatics in Developing Countries. 5, 60-88.

12. Heller RF. 2009. Experience with a "social model" of capacity building: the Peoples-uni. Hum Resour Health. 7(43). PubMed

13. Oluoch T, Santas X, Kwaro D, Were M, Biondich P, et al. 2012. The effect of electronic medical record-based clinical decision support on HIV care in resource-constrained settings: a systematic review. Int $J$ Med Inform. 81, e83-92. $\underline{\text { PubMed }}$ http://dx.doi.org/10.1016/j.ijmedinf.2012.07.010

14. Bryan C, Boren S. 2008. The use and effectiveness of electronic clinical decision support tools in the ambulatory/primary care setting: a systematic review of the literature. Inform Prim Care. 16, 79-91. PubMed

15. Edejer TT-T. 2000. Disseminating health information in developing countries: the role of the internet. BMJ. 321(7264), 797-800. PubMed http://dx.doi.org/10.1136/bmj.321.7264.797

16. Jimoh L, Pate M, Lin L, Schulman K. 2012. A model for the adoption of ICT by health workers in Africa. Int $J$ Med Inform. 81(11), 773-81. PubMed http://dx.doi.org/10.1016/j.ijmedinf.2012.08.005

17. Lund S, Nielsen BB, Hemed M, Boas IM, Said A, et al. 2014. Mobile phones improve antenatal care attendance in Zanzibar: a cluster randomized controlled trial. BMC Pregnancy Childbirth. 14(29). PubMed

18. Hirst J, Jeffery H. 2013. Education, audit, and outreach to prevent maternal mortality. Lancet. 382, 108-10. PubMed http://dx.doi.org/10.1016/S0140-6736(13)60906-X

19. Dumont A, Fournier P, Abrahamowicz M, Traoré M, Haddad S, et al. 2013. Quality of care, risk management, and technology in obstetrics to reduce hospital-based maternal mortality in Senegal and Mali (QUARITE): a cluster-randomised trial. Lancet. 382, 146-57. PubMed http://dx.doi.org/10.1016/S0140-6736(13)60593-0

20. Grol R, Grimshaw J. 2003. From best evidence to best practice: effective implementation of change in patients' care. Lancet. 362, 1225-30. PubMed http://dx.doi.org/10.1016/S0140$\underline{6736(03) 14546-1}$ 